\title{
Modeling Access Mode Choice for Inter-Suburban Commuter Rail
}

\author{
Åsa Bergman, John Gliebe, James Strathman \\ Portland State University
}

\begin{abstract}
This paper presents an analysis of access mode choice by riders of one of the first U.S. suburb-to-suburb commuter railroads, the Westside Express (WES), in the Portland, Oregon metropolitan area. The study uses on-board survey data collected by the region's transit agency, Tri-Met, during WES's first year of operation. The data include observed access mode choices, historical mode usage, and subjective assessment of WES attributes. A hierarchical choice model was estimated, using attributes of the access trip, station areas and rider characteristics. The estimation results revealed pre-WES-mode inertia effects in choosing drive access, pro-sustainability attitudes in choosing bike access, the importance of comfort to light rail and auto users, and strongly positive station-area effects of feeder bus lines and parking provision. The hierarchical choice model revealed significant substitution effects between drive and light rail modes and between bike and walk modes. This study provides potentially valuable insights to agencies for the purposes of station-area planning and targeted marketing efforts.
\end{abstract}

\section{Introduction}

In recent years, transit agencies have been trying more aggressively to attract suburban choice riders by extending rail service to areas traditionally dominated by automobile travel. Understanding the needs and preferences of current and potential transit riders is fundamental to developing and providing an attractive 
service, but little is known about inter-suburban commuters and how they differ from more familiar hub-and-spoke commuter rail riders and urban transit riders.

Transit access and egress experiences are one important difference. Walk access dominates city transit and, consequently, most urban access mode choice studies focus on walking (Cervero 1995; Loutzenheiser 1997). Commuter rail riders, however, often live or work, or both, in the suburbs and depend on non-walk modes for train access. Access modes for commuter rail have received scant attention to date, and even less is known about the preferences and sensitivities of inter-suburban commuter rail riders.

This study applies discrete choice modeling to data from an onboard survey conducted by TriMet in $\mathbf{2 0 0 9}$ on the Westside Express Service (WES), an inter-suburban commuter rail serving the western suburbs of Portland, Oregon. The objective is to learn more about suburban commuter rail access in general and WES riders in particular by estimating models of access mode choice with the aim of supporting targeted marketing and station-area planning efforts. The analysis covers both home and non-home origins and considers socio-economic, trip-context, station area and service variables, as well as survey respondents' attitudes. To our knowledge, this is the first study of access mode choice for suburb-to-suburb commuter rail.

\section{Background}

WES began operations in January 2009 as a single suburb-to-suburb line with five stations over 14 miles of existing freight tracks serving the heavily-traveled I-5 and OR Highway 217 corridor during rush hours. With only one connection to TriMet's light rail network, WES deviates from the conventional hub-and-spoke structure, making commuter rail transit available to those who both live and work in the suburbs.

Previous studies have found that access and egress factors, such as easy access to additional transportation, adequate parking, centrally-located stations, and attractive pricing, play important roles in attracting commuter rail riders (Cervero and Kockelman 1997; MARC 2002; Taylor and Fink, 2001). In terms of access mode shares, the majority of riders using Toronto's GO Rail system drove and parked (56\%), followed by bus at 16 percent and walk at 11 percent (Wells 1996). In their study of Chicago's Metra system, Kurth et al. (1991) likewise found park-and-ride to be the dominant access mode (47\%), but found higher walk access than bus access ( $22 \%$ and $11 \%$, respectively). A 1994 survey of Florida's Tri-Rail revealed an access mode split of 48 percent park-and-ride, 38 percent transit, and 14 percent walk (Hadj-Chikh 1998). 
Compared to city transit, commuter rail riders' tolerance for walking tends to be higher. Walking dominates short access trips of 0.5 to 0.7 miles, accounting for up to 80 percent of the mode split (Evans 2007; Debrezion 2009). For longer access distances, car or feeder transit services dominate. A BART survey found that 80 percent of access trips exceeding one mile to suburban stations were made by car (Cervero 2001).

Urban form, station-area factors, and area demographics also can affect access mode choice. In Washington, D.C., transit station area population density and walk access mode share were positively correlated (Kurth et al. 1991). Loutzenheizer (1997) found that availability of additional transit positively influenced transit access to BART commuter rail, but noted that individual characteristics such as gender, ethnicity, age, and car availability explained access mode choice better than land use and urban design variables. A 2003 study in California found that highincome transit riders residing close to rail stations were more likely to walk and bike to rail transit than other income groups (Evans 2007).

Access and egress mode choices differ, as fewer modes are typically available for the egress trip. Even so, findings from an egress mode study on Metra commuter rail trips in Chicago may be instructive. Kurth et al. (1991) found average egress walk time was 0.6 miles ( 12 minutes), noting that this was longer than the half-mile often used as a maximum walk distance for light rail transit. Moreover, the estimated value of time for the egress mode choice model was about half the value of time for the regional mode choice model.

\section{About the WES Survey}

In the summer of 2009, after WES had operated for six months, TriMet conducted an extended on-board origin-destination survey (TriMet 2009), collecting data on origins and destinations, previous travel modes, socioeconomic variables, pass holder status, and respondent attitudes. It should be noted that the survey was trip-based, not person-based, so some individuals may have taken it more than once. Highlights include:

- Before WES existed, 42 percent of respondents made the same trip by car and 47 percent by bus.

- 90 percent of trips were made by self-reported frequent or regular transit users. 
- 35 percent of trips were made by people whose fares were subsidized by employers.

- Respondents' income distribution was bimodal, with a larger share of highincome riders than is typical for peak hour trips on TriMet overall.

- 63 percent of WES trips were made by males, and 75 percent of trips by Caucasians.

- WES riders agreed somewhat or strongly with all image statements about WES, such as freedom from stress and traffic, reliability and good connection with other transit modes. Riders described WES as "fast" and "comfortable," but wished for extended hours of operation and higher frequency.

\section{Access Mode}

Nine out of ten WES trips were home-based, (i.e., home was either the origin or destination). Home was the origin for 56 percent of home-based trips. Commuting (one end being work or school) comprised 77 percent of trip purposes. In general, the survey showed that WES attracts high proportions of bus and walk access for both home and non-home origins and relatively low proportions of car access trips, compared with the other commuter rail access model studies reviewed above. Figure 1 shows access mode shares for home origins, in which bus (28\%) and car (27\%) dominate, followed by walk (20\%). For non-home access trips, car tends to be unavailable, and bus is the dominant access mode, distantly followed by walk and light-rail transit (LRT), as shown in Figure 2.

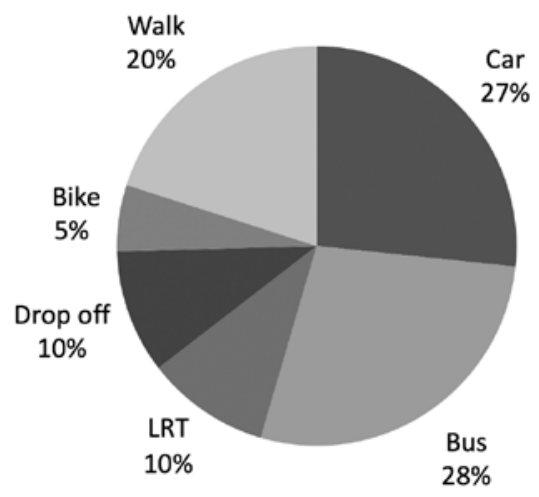

Figure 1. Access mode shares from home origins 


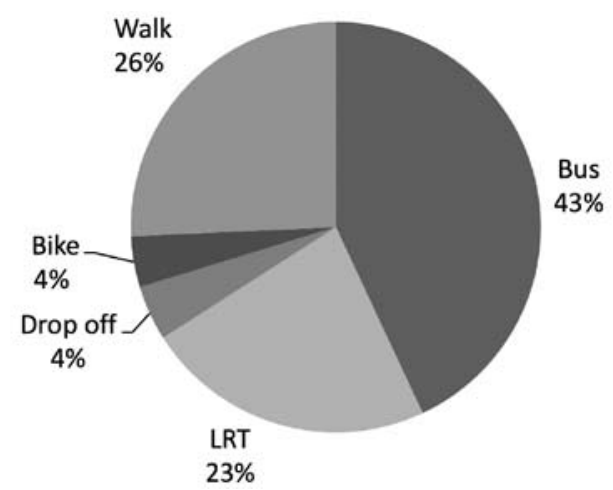

\section{Figure 2. Access mode shares from non-home origins}

Table 1 shows travel times by chosen access mode. Here, travel time is defined as the sum of in-vehicle, walking, initial wait, and transfer wait times for motorized modes, as derived from modeled network times used in the mode choice analysis described below. For reasons discussed below, this excluded observations in which walk and bike times exceeded the 85th and 95th percentile cutoffs, respectively. The long median travel times for bus and LRT suggest that, when coupled with other transit modes, WES represents one of two or more legs of a longer trip and is not necessarily the principal mode.

\section{Table 1. Median, Mean and Max WES Access Times}

Time (minutes, including wait and transfer)

\begin{tabular}{lrrr} 
& Median & Mean & Max \\
\hline Car & 7 & 11 & 51 \\
Bus & 30 & 34 & 121 \\
LRT & 22 & 24 & 73 \\
Drop-off & 5 & 7 & 25 \\
Bike & 13 & 19 & 55 \\
Walk & 8 & 13 & 59
\end{tabular}

Figure 3 shows access mode shares by distance. The median access trip was 1.7 miles (mean 2.75 miles). Walk access is the dominant mode at distances shorter than onehalf mile, but drops sharply thereafter. Between one-half and one mile, mode shares are relatively equal between car and bus. For distances of one to five miles, bus is the major access mode. LRT holds the largest share for trips greater than five miles, but this is limited to trips accessing WES at the Beaverton station. In contrast to previously mentioned studies, WES auto access is notably low even at longer distances. 


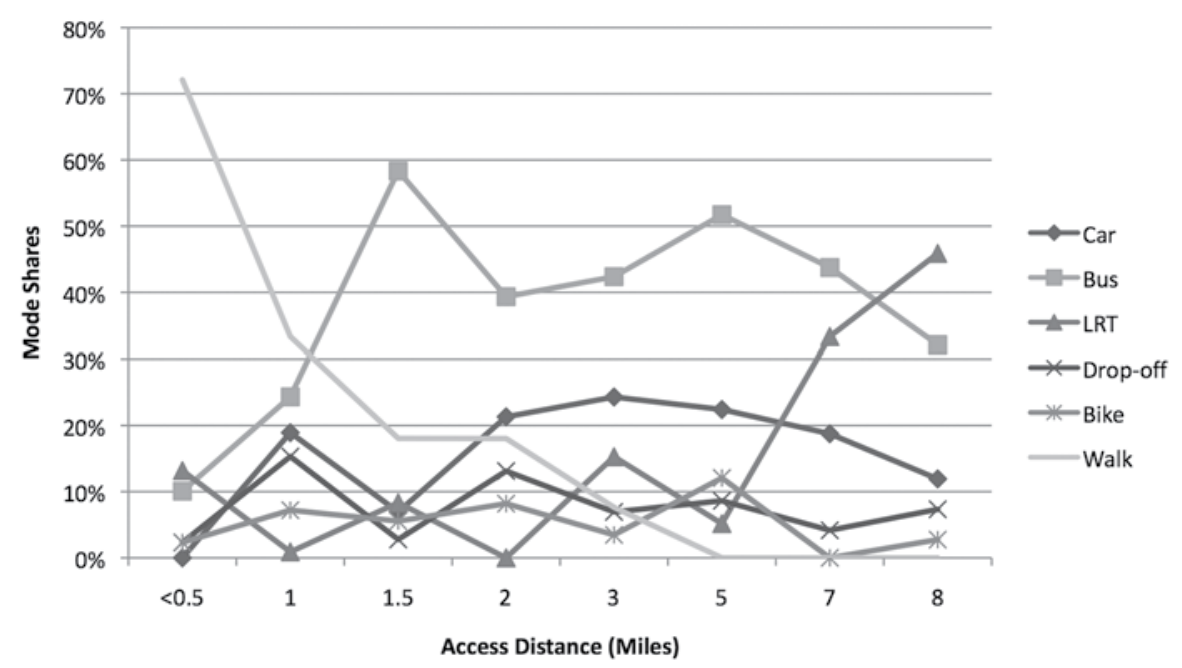

Figure 3. Access mode by distance

The survey used the three income categories listed in Figure 4. As expected, bus is a dominant mode share among the low income group, whereas car has the largest mode share in the high-income group, just below 30 percent. In contrast to the low income group, walk and bus access have equal mode shares among high-income riders.

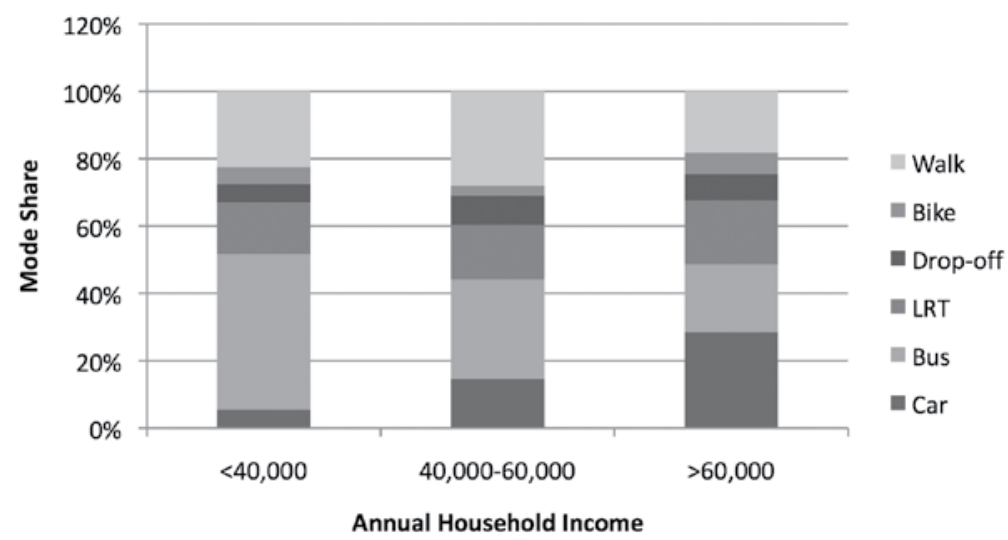

\section{Figure 4. Access mode by annual household income}

Access mode choice also varied substantially by WES station. For example, Beaverton is the only station with LRT access, which is the main access mode, but has no parking spaces and consequently supports very little (5\%) car access. Tigard has the highest share of bus access (36\%), while Tualatin is characterized by walk access (39\%). 


\section{Methodology}

To explore the behavior of individuals making a choice between alternative access modes, this study used discrete choice modeling methods (McFadden 1974; Ben Akiva et al. 1985). In discrete choice models, the probability of choosing a particular alternative is proportional to the difference between its estimated utility and the estimated utility of other available alternatives. Utility is defined as a linear function including variables representing attributes of the modes (e.g., travel time, cost, frequency), decision maker (e.g., income, auto ownership, age) or attributes of the environment in which the decision is made (e.g., population density). Utility function coefficients are estimated using maximum likelihood methods.

The multinomial logit (MNL) model is the simplest form, assuming that random error terms are identically and independently distributed (IID). A consequence of this restriction is the assumption of equal competition among alternatives. For example, in the MNL, the introduction of service improvements to an existing mode reduces the probability of other existing modes in proportion to their probabilities before the change. In reality, however, some alternatives are likely to be closer substitutes than others. The IID property can be overcome by using more flexible, complex model forms. In this study, we also estimated a Nested Logit (NL) model, which relaxes the independence assumption and can accommodate different degrees of similarity between subsets (nests) of access model alternatives.

\section{Choice Set Creation}

Logit mode choice models require the analyst to account for not only the observed choice, but also the set of alternatives that could have been chosen by each respondent. We supplemented the WES survey with trip-specific data on motorized and non-motorized travel times, transit availability and transfer times, costs, and previous on-board surveys. We defined a universal choice set consisting of six accessmode alternatives: car (drive and park), bus (with walk access), LRT (with walk access), drop-off (ride share), bike, and walk. From this universe of alternatives, we then created a set of "available" alternatives for each respondent in the survey.

Auto distances and travel time skims for pairs of traffic analysis zones (TAZ) were retrieved from the Portland regional travel demand model for all motorized modes (Metro 2005). Car was made available only for trips where the origin was home. The WES survey did not recover information on auto ownership. Based on auto ownership information gathered from onboard bus and express bus surveys in the WES corridor before WES existed, car was set as an available mode to 90 percent of trips in the dataset. Car was removed from the choice set for the one-tenth of surveys 
for which all of the following was true: Low income household ( $<\$ 40,000$ per year)+ trip start at home + chosen access mode not car or drop-off + travel mode before WES existed not car or drop-off.

Because fares paid for WES also cover transit access modes, only Car was assumed to have an additional monetary cost, calculated based on an average fuel consumption of 23 miles per gallon and a summer 2009 gasoline price of $\$ 2.73$ per gallon (US DOE 2009; Oregongasprices.com 2009).

The cost for drop-offs was set to 0.75 of drive and park cost, to reflect the two possible scenarios where a person can be dropped off on the driver's way (shared cost) or where the driver goes out of his or her way to drop off the WES rider (extra cost).

In Metro's transit travel time skims, bus is available if the distance from a TAZ centroid to the nearest bus line is under 0.25 miles. For LRT, the cutoff is 0.5 miles. Initial and transfer waits are calculated as half the headway of the nearest bus line, and walk access time is based on the distance from the TAZ centroid to the nearest bus line (Metro 2008). LRT was available only for trips accessing WES at Beaverton transit center.

A model developed by Broach et al. (2009) was used to produce least-cost path distances and travel times for bike and walk access. The model used a detailed network with bike paths. Utility-weighted distances, taking into account factors such as grade, presence of bike facilities, and car traffic volumes, were used instead of network distances. The 95th percentile, 8.5 miles, was chosen as a cutoff for availability for the universal choice set to retain a sufficiently large number of observations. The reported median access distance was 1.7 miles (mean 2.6 miles).

The fine level of detail in the bike network also made it useful for estimating shortest path distances for walk access. Median walk distances to WES were long: 0.54 miles (over 10 minutes), further than typically assumed walk distances to urban rail transit. The 85th percentile, 3 miles or 1 hour of walking, was set as the upper limit for walk availability.

The final dataset in the access mode choice estimation model retained 732 observations, or 77 percent of the original. Reasons for exclusion included missing information, origins outside the study area, and unrealistically long walk or bike distances.

\section{Independent Variables}

Explanatory variables used in the model estimation are listed in Table 2. 


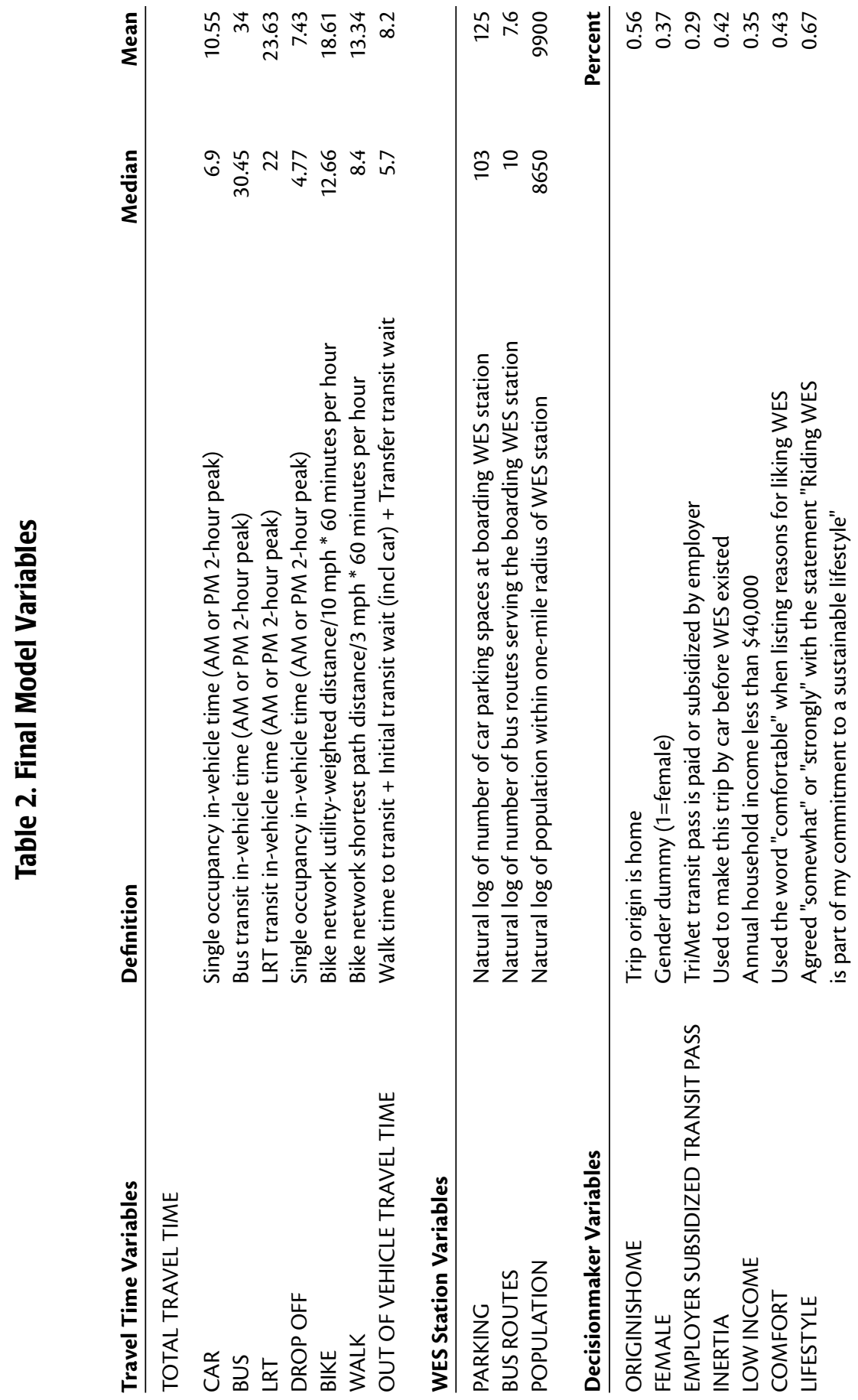




\section{Model Results}

Findings from previously published studies of access to urban rail transit and commuter rail, together with knowledge of WES and its service area, were brought together to form hypotheses about factors influencing the choice of all included access modes. Hypothesized relationships were tested in the model and typically retained at a 95\% confidence level. While the final model specification includes mainly statistically significant variables, the discussion of the model results includes mention of a few theoretically plausible, yet statistically insignificant effects. Parameter estimates for the preferred multinomial and nested logit model specifications are presented in Table 3, and the preferred nesting structure illustrated in Figure 5.

\section{Table 3. Preferred MNL and NL Models}

\begin{tabular}{lrr}
\hline Preferred MNL and NL models & \multicolumn{1}{l}{ MNL } & \multicolumn{1}{l}{ NL } \\
\hline Log Likelihood at zero coefficients & -1038.02 & -1038.02 \\
Log Likelihood at constant & -816.06 & -816.055 \\
Log Likelihood at convergence & $\mathbf{- 6 9 9 . 8 7}$ & $\mathbf{- 6 7 9 . 4 6 7}$ \\
Rho-squared w.r.t. zero & 0.326 & 0.345 \\
Rho-squared w.r.t zero Adjusted & 0.326 & 0.324 \\
Rho-squared w.r.t. constants & 0.142 & 0.167 \\
Rho-squared w.r.t. constants Adjusted & 0.142 & 0.146 \\
Number of cases & 732 & 732
\end{tabular}

\section{Parameter t-stat Parameter t-stat}

\section{Constants:}

Car

Bus

LRT

Drop off

Bike

3.684

2.065

0.935

1.049

Walk

0.505

6.621

5.216

6.478

0.863

$-0.889$

$-1.865$

0.946

1.395

$-0.015$

$-0.016$

$-1.64$

$-0.84$

$-2.273$

$-0.89$

\section{Generic variables:}

Travel cost (\$, car only)

Total travel time (minutes)

In-vehicle travel time motorized modes

Travel time non-motorized modes

Out of vehicle travel time (walk time, initial and transfer wait)

$\begin{array}{llll}-0.602 & -1.453 & -0.911 & -1.932 \\ & & & \\ -0.023 & -1.772 & -0.049 & -2.453 \\ -0.049 & -6.745 & -0.079 & -4.07 \\ -0.005 & -0.428 & -0.027 & -1.308\end{array}$


Table 3. Preferred MNL and NL Models (cont'd)

\begin{tabular}{|c|c|c|c|c|}
\hline & Parameter & t-stat & Parameter & t-stat \\
\hline \multicolumn{5}{|l|}{ Mode specific variables: } \\
\hline \multicolumn{5}{|c|}{ Log of car parking spaces at WES station } \\
\hline Car & 0.34 & 3.944 & 0.365 & 2.897 \\
\hline \multicolumn{5}{|c|}{ Used to drive this trip before WES existed (inertia) } \\
\hline Car & 1.507 & 5.045 & 2.536 & 5.465 \\
\hline \multicolumn{5}{|c|}{ Employer paid or subsidized transit pass } \\
\hline Car & 0.642 & 2.259 & 1.181 & 2.673 \\
\hline \multicolumn{5}{|c|}{ "Comfort" as main reason for liking WES } \\
\hline Car & 0.685 & 2.38 & 0.734 & 1.726 \\
\hline LRT & 1.1 & 3.066 & 1.282 & 2.644 \\
\hline \multicolumn{5}{|c|}{ Low income household ( $<\$ 40,000$ annual income) } \\
\hline Bus & 0.62 & 3.194 & 0.698 & 2.137 \\
\hline \multicolumn{5}{|l|}{ Log of bus routes at WES station } \\
\hline Bus & 0.697 & 4.286 & 1.447 & 4.236 \\
\hline \multicolumn{5}{|l|}{ Origin is home } \\
\hline Drop off & 1.128 & 3.426 & 1.079 & 3.326 \\
\hline \multicolumn{5}{|l|}{ Female } \\
\hline Bike & -1.341 & -2.7 & -1.421 & -2.559 \\
\hline \multicolumn{5}{|c|}{ "Riding WES is part of my sustainable lifestyle" } \\
\hline Bike & 1.127 & 2.429 & 1.229 & 2.271 \\
\hline \multicolumn{5}{|c|}{$\begin{array}{l}\text { Log of population density within one mile of } \\
\text { WES station }\end{array}$} \\
\hline Walk & 0.586 & 2.927 & 0.611 & 2.249 \\
\hline \multicolumn{5}{|l|}{ Nested test (against MNL model) } \\
\hline Number of nests & & & & 2 \\
\hline Chi-squared vs MNL,-2*(LL_R-LL_U) & & & & 40.813 \\
\hline Critical chi-squared (95\%) & & & & 5.99 \\
\hline Rejection significance & & & & $<.0001$ \\
\hline \multicolumn{5}{|l|}{ Nesting coefficients } \\
\hline Motorized 1 (drop off) & & & $1\left(^{*}\right)$ & \\
\hline Motorized 2 (car,bus,LRT) & & & 0.353 & 8.371 \\
\hline Non-motorized (bike, walk) & & & 0.586 & 3.063 \\
\hline
\end{tabular}




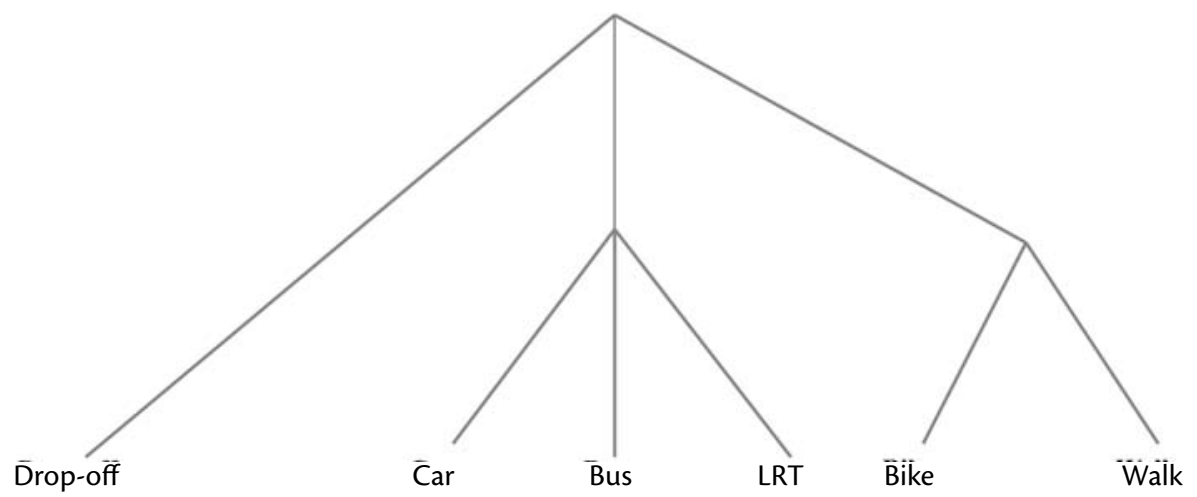

Figure 5. Preferred nesting structure

\section{Model Fit Statistics}

The NL model with the highest log likelihood value, -679.47 , predicted access mode choice better than the multinomial logit specification ( $p<.0001)$. The rho-squared value is a log likelihood ratio between 0 and 1 , used to indicate goodness of fit of the model, where a value of 1 implies all mode choices are predicted correctly. The rho-squared with respect to $0,0.324$, is an acceptable model fit considering limitations of the data. The adjusted rho-squared with respect to constants, 0.146 indicates that the independent variables provided explanation in addition to the model constants.

After testing several nesting structures, the preferred nesting structure illustrated in Figure 5 was chosen, based on goodness of fit, reasonableness of parameter estimates and theoretical validity. In this structure, car, bus and LRT belong to the same nest because they share more unexplained variance, while drop-off differs from the motorized modes. Similarly, bike and walk were closer substitutes and were placed in the same nest. The two nesting coefficients were estimated at the lowest level in the model. Nesting parameters with values closer to 0 represent greater similarity between alternatives within that nest, while values closer to one are statistically more independent. A Wald test demonstrated that the motorized and non-motorized nests were significantly different from $1(0.353, t 8.371$ and $0.586, t 3.063$, respectively), thereby validating this structure.

\section{Time and Cost Variables}

In mode choice models, it is assumed that shorter travel times and lower costs increase the utility of an alternative. Therefore, we expect the coefficients to be negative for in-vehicle travel time, walk time to transit, initial wait for car and 
transit, transfer wait for transit, and out-of-pocket costs. In preliminary estimation attempts, walk time, initial wait and transfer wait performed closest to these expectations when estimated together as out-of-vehicle travel time. En-route travel time was also separated into motorized and non-motorized modes to reflect the expectation that walking and biking are more physically demanding travel modes.

The coefficient on out-of-vehicle time was negative but, contrary to expectations, not significant $(-0.027, t-1.308)$. The coefficient on cost was negative and barely significant at the $95 \%$ confidence level $(-0.911, t-1.932)$. As expected, the in-vehicle travel time coefficient for motorized modes was negative and significant $(-0.049$, $t-2.453)$, while the non-motorized travel time coefficient had a stronger negative magnitude and significance $(-0.079, \mathrm{t}-4.07)$. These results have implications for the value of time implied by the model.

\section{Implied Value of Time}

To test the reasonableness of the time and cost coefficients, the implied value of time was calculated, in dollars per hour, as follows:

$$
\frac{\beta \text { In-Vehicle Travel Time }}{\beta \text { Cost }} \times 60=\text { Dollar value of time per hour }
$$

For models in which one predicts the main mode, not just the access mode, this value is expected to be roughly one-quarter to one-half of an hourly wage rate (Koppelman and Bhat 2006). Table 4 shows the in- and out-of-vehicle value of time in dollars for motorized and non-motorized modes for the nested logit model.

\section{Table 4. Preferred NL Model Implied Value of Time}

\section{Preferred NL model}

\section{Value of time}

In-vehicle travel time \$ per hr (motorized)

Travel time \$ per hr (non-motorized)

Wait and transfer time \$ per hr
3.20

5.20

1.77

Detailed information on WES rider incomes was not available. More riders were included in the below $\$ 40,000$ and above $\$ 60,000$ bins than in the middle income category. If the median hourly wage is taken to be $\$ 20$ per hour, the motorized invehicle travel time value of time would be one-sixth of the hourly wage, which is low compared with the ratios expected for main mode choice models. The implied value of time for non-motorized modes is closer to expectations at approximately 
one-fourth of the hourly wage. The out-of-vehicle time parameter is problematic, not only because it is statistically non-significant, but also because it implies a lower value of time than in-vehicle travel time. Best practices in mode choice modeling hold that travelers regard waiting, transfer, and walk access times as two to three times more onerous than in-vehicle time (Koppelman and Bhat 2006).

The non-significance of the out-of-vehicle parameter and hence low value of time estimate may be partially due to a lower overall value of time for WES riders. Unlike the larger auto-oriented population, they seem to tolerate longer line-haul travel times and longer walk and bike access distances. These results seem to be consistent with the study by Kurth et al. (1991) on Chicago-area commuter rail egress trips, which reasoned that low values of time for egress trips might reflect lower willingness to pay additional costs for travel from commuter rail stations to final destinations. Another contributing factor is that the zone-based nature of the transit networks and aggregation of peak and off-peak average headways is likely to produce imprecise measurements of the experienced waiting times and inaccurate assumptions regarding bus stops used.

\section{Rider Characteristics}

It was hypothesized that riders may have formed habitual preferences for the modes they used for this trip prior to the existence of WES. This "inertia effect" was found to be significant only for ex-car drivers, who comprised 42 percent of the sample. The ex-driver dummy variable was strongly positive and significant $(2.536, t 5.465)$, indicating that people who had previously driven the entire trip were now more likely to drive to and park at the WES boarding station. We theorized that WES riders with employer-sponsored transit passes would be more prone to accessing WES by transit modes. Contrary to our expectations, riders with employer-sponsored passes ( $35 \%$ of sample) were found to be significantly more likely to drive to WES $(1.181, t 2.673)$. This likely is related to motivations behind employer sponsored pass programs, such as targeting former car commuters.

While low-income riders were expected to access WES by bus, LRT, walk, or bike (i.e., modes that incur no extra cost in addition to the WES fare), the estimation results supported this hypothesis only for bus (0.698, t 2.137). Unlike the Bay Area study by Evans (2007), our study did not find a significant relationship between walkaccess propensity and high-income earners whose trips originated within a mile of the WES boarding station. Nor did we find a significant relationship between walk access propensity and ex-drivers with origins within a mile of WES stations. It may be argued that the suburban environment combined with the strong "car inertia" 
effects discussed above, makes walking and biking less attractive and that this has a stronger influence on the disutility of walking than distance alone.

Ride sharing tends to be more common among members in the same household. We tested for this by including a dummy variable for trips originating at home, and found that WES riders starting from home were more likely to be dropped off than trips starting elsewhere $(1.079, t 3.326)$. Home-origin proved to be the only significant predictor of the drop-off mode. In urban mode choice studies, females often are found to be less likely than males to travel by bike (Broach et al. 2009). Likewise, gender had a significant effect on choosing bike access for WES riders (-1.421, $t-2.559)$.

\section{WES Attributes}

We theorized WES riders' subjective ratings of WES attributes could reveal preferences for certain access modes. We detected a "comfort factor," where riders who described the commuter rail as "comfortable" and cited this as the main reason they liked WES were significantly more likely to access it by LRT $(1.282, t 2.644)$. The relationship between comfort and the choice of car as the access mode also was significant in the MNL model $(0.685, t 2.38)$, but the significance of this parameter dropped to the $90 \%$ confidence level $(0.734, t 1.726)$ in the NL model, suggesting this is not a well-defined variable. Nonetheless, it was retained in the model as an interesting value statement seemingly shared between LRT and car users.

Further, the survey probed WES rider sustainability values with the statement, "Riding WES is part of my commitment to a sustainable lifestyle." We hypothesized that those who agreed with this sustainability statement would be more likely to access the train by all non-automobile modes. Interestingly, this effect was found significant only for bike access (1.229, t 2.249).

\section{Station Area Variables}

Based on findings from other studies, it was hypothesized that greater parking supply would lead to more car access trips and more transit line connections would produce more bus access trips. To account for the non-linear and diminishing effect of additional car parking spaces, the natural log of car parking spaces was specified and yielded a positive and significant coefficient (0.365, t 2.897), confirming the hypothesis. Using the natural log of bus routes serving each station, it was found that the probability of riding the bus to access WES increases with the number of connecting bus routes $(1.477, \mathrm{t} 4.236)$.

In the aforementioned Washington, D.C. study (Kurth et al. 1991), stations with higher population densities were found to have higher proportions of pedestrian access. We 
found that WES riders are more likely to walk to the train in areas with higher population density (0.611, t 2.249). More direct measures of urban design, such as number of intersections, traffic volumes, or even percentage streets with sidewalks, would likely produce a stronger indicator of "walkability" (Schwanen and Mokhtarian 2005); however, creating these variables was beyond the scope of our study.

As WES is a small commuter rail line with only five stations, attributes or travel behaviors associated with individual stations could have an unduly large influence in the model. To control for this, station dummy variables were tested, but no significant relationships between access mode and station were found. Nevertheless, the estimated constant for LRT is likely to pick up some station-specific effects due to it being available only at the Beaverton WES station.

\section{Elasticities: Employing the Model}

Elasticity computations can show how the probability of choosing an access mode changes in response to a change in an observed variable. This is useful for analyzing service or station attributes, over which the agency has some control. For example, if the number of car parking spaces at a WES station were increased, we could calculate the impact of this change on car-access mode share (direct elasticity) and could predict the extent to which other access modes would lose shares (cross-elasticity).

Using the estimated coefficients from the NL model, we tested the purely hypothetical situation of adding up to 100 car parking spaces at the Beaverton WES station, which has no park-and-ride today, despite the fact that nine survey takers drove and parked near this station. Because the elasticity computation requires a starting value above 0 , it was assumed that the station starts out with four car parking spaces. The log of car parking spaces variable was used to capture the diminishing effect of adding more spaces. Table 5 shows the outcome of this exercise. Expanding to a total of 100 parking spaces would result in a 319 percent increase, or 29 additional car access trips to that station. The new car access mode share would be 13.7 percent, and the shares of other modes would be reduced. Following from the structure of the nested model, the largest effect would be on LRT and bus, which share the same nest as car, with smaller negative effects on the probability of choosing alternative drop-off, bike, and walk.

It is important to note that, due to the scope of this study, these elasticity calculations assume that total demand is fixed, and do not account for the possibility of attracting new WES riders, which might occur if additional parking were provided. 


\section{Table 5. Changes in Mode Shares Resulting from Addition of Parking Spaces}

\section{Beaverton Transit Center}

\begin{tabular}{lr}
\hline Current parking spaces & 4 \\
Total spaces after addition & 100 \\
\hline
\end{tabular}

\begin{tabular}{lrrrrrrr} 
Beaverton WES access mode shares & Car & Bus & LRT & $\begin{array}{c}\text { Drop- } \\
\text { off }\end{array}$ & Bike & Walk & Total \\
\hline Original mode shares & $3.30 \%$ & $31.60 \%$ & $41.80 \%$ & $8.00 \%$ & $2.90 \%$ & $12.40 \%$ & $100 \%$ \\
Elasticity & 1.377 & -0.056 & -0.056 & -0.017 & -0.017 & -0.017 & \\
Percent change & $319.80 \%$ & $-13.03 \%$ & $-13.03 \%$ & $-3.85 \%$ & $-3.85 \%$ & $-3.85 \%$ & \\
New mode shares & $13.70 \%$ & $27.50 \%$ & $36.40 \%$ & $7.70 \%$ & $2.80 \%$ & $11.90 \%$ & $100 \%$ \\
\hline
\end{tabular}

\section{Conclusion}

The objective of this study was to learn how WES commuter rail riders choose access modes. This study found that station area attributes such as car parking spaces, connecting bus routes, and population density are some of the most important predictors of WES access mode choice, which is consistent with other urban rail transit access studies. In addition, we found significant relationships between certain rider attitudes and access mode choice, namely a link between appreciation for comfort and the propensity to access WES by LRT or car, and a link between pro-sustainability attitudes and bike access. Moreover, this study showed clear evidence for the preferences of ex-car commuters for driving to and parking at commuter rail stations. Employer-sponsored pass holders were also significantly more likely to access WES by car.

This type of study could be improved by including in future surveys questions related to auto and bike availability, which is critical to accurate construction of choice sets. In addition, some measurement problems related to transit sub-mode access, walk and wait times, and transfers could be remedied by point-to-point routing of transit trips and increased attention to schedule detail, which would require a more advanced transit network modeling tool than is currently available for the Portland region. As shown by Krizek and El-Geneidy (2007) in a Minneapolis-St. Paul transit market analysis, system reliability is also an important factor in travel mode choice. This could be explored for WES through additional survey questions related to its importance and respondent travel time buffers.

Current WES riders are similar to commuter rail riders elsewhere in their tolerance for long access travel times, irrespective of access mode, but differ in their 
greater propensity to use non-auto access modes, particularly bus and walk. This preference for non-auto access modes, combined with the fact that WES is the only commuter rail line in the region, is just 14 miles in length, and is designed to connect suburbs, suggests that it may function more like a link in the regional transit network than a distinct primary mode. The study of a single suburb-to-suburb commuter rail line is not enough, however, to make any conclusive statements about the extent to which suburb-to-suburb commuter rail riders may differ from conventional hub-and-spoke commuter rail.

At the time of the study, WES had operated for only six months and was characterized by a small and enthusiastic group of riders, some of whom were likely trial users. Future analysis is likely to find a more established ridership. It would be especially interesting to follow car-accessing employer-sponsored transit pass holders over time to find out if they can be retained. Future work of this type should expand the scope of analysis to consider the entire mode choice decision and include the joint choices of access, main and egress modes together with other main modes, such as the automobile.

\section{References}

Ben-Akiva, M., and S. Lerman. 1987. Discrete Choice Analysis: Theory and Application to Travel Demand. Cambridge: The MIT Press.

Broach, J., J.Gliebe, and J. Dill. 2009. Development of a multi-class bicyclist route choice model using revealed preference data. Paper presented at the 12th International Conference on Travel Behavior Research, Jaipur, India.

Cambridge Systematics. 2002. NCTCOG Mode Choice Model estimation documentation.

Cervero, R., and M. Duncan. 2002. Residential self selection and rail commuting: A nested logit analysis. 2008 revision.

Cervero, R. 2001. Walk-and-ride: Factors influencing pedestrian access to transit. Journal of Public Transportation 3(4): 1-23.

Cervero, R., and K. Kockelman. 1997. Travel demand and the 3Ds: Density, diversity and design. Transportation Research D 2(3): 199-219.

Debrezion, G., E.Pels, and P. Rietveld. 2009. Modelling the joint access mode and railway station choice. Transportation Research E 45: 270-283. 
Evans, J., R. Pratt, A. Stryker, and J. Kuzmyak. 2007. TCRP Report 95: Traveler Response to Transportation System Changes. Chapter 17: Transit Oriented Development. Transit Cooperative Research Program, Transportation Research Board, Washington.

Hadj-Chikh, G., and G. Thompson. 1998. Reaching jobs in the suburbs. Tri-Rail in South Florida. Transportation Research Record 1618:14-21.

Koppelman, F., and C. Bhat. 2006. A Self-instructing course in mode choice modeling: Multinomial and Nested Logit models. Prepared for U.S. Department of Transportation and Federal Transit Administration.

Krizek, K., and A. El-Geneidy. 2007. Segmenting preferences and habits of transit users and non-users. Journal of Public Transportation 10(3): 71-94.

Kurth, D.L., C. Chang, and P. Costinett.1991. Enhancements to circulator-distributor models for Chicago central area based on recently collected survey data. Transportation Research Record 1443: 11-20.

Loutzenheiser, D. 1997. Pedestrian access to transit: Model of walk trips and their design and urban form determinants around Bay Area Rapid Transit stations. Transportation Research Record 1604: 40-49.

McFadden, D. 1974. Conditional logit analysis of qualitative choice behavior. In P. Zarembka (ed), Frontiers in Econometrics, 105-142. New York: Academic Press.

Metro. 2008. Metro travel forecasting 2008 trip-based demand model methodology report.

Mid-America Regional Council (MARC). 2002. Commuter rail feasibility study.

Oregongasprices.com. 2009. Historical price charts. Accessed August 30, 2010. http://www.oregongasprices.com/retail_price_chart.aspx.

Schwanen, T., and P. Mokhtarian. 2005. What affects commute mode choice: neighborhood physical structure or preferences towards neighborhoods? Journal of Transport Geography 13(1): 83-99.

Taylor, B., and C. Fink. 2001. The Factors influencing transit ridership: A review and analysis of the ridership literature. Working paper. UCLA Department of Urban Planning.

Train, K. 2009. Discrete Choice Modeling Methods with Simulation. Cambridge: Cambridge University Press. 
TriMet. 2010. Westside express service passenger study.

U.S. Department of Energy. 2009. Fuel Economy Guide.

Whately, L., B. Friel, and G. Thompson. 1997. Analysis of suburb-to-suburb commuter rail potential: Metrolink in southern California. Transportation Research Board Conference Proceedings 2(8): 175-18.

\section{About the Authors}

ÅSA BERGMAN (abergman@pdx.edu) recently completed a master's degree in Urban and Regional Planning from Portland State University.

JoHn Gliebe (gliebej@pdx.edu) is an assistant professor in the Nohad A. Toulan School of Urban Studies and Planning at Portland State University.

JAMES StrathmaN (strathmanj@pdx.edu) is a professor in the Nohad A. Toulan School of Urban Studies and Planning at Portland State University and director of the Center for Urban Studies. 